\title{
Branchiootic syndrome
}

INSERM

\section{Source}

INSERM. (1999). Orphanet: an online rare disease and orphan drug data base.

Branchiootic syndrome. ORPHA:52429

Branchiootic syndrome is a rare, genetic multiple congenital anomalies syndrome characterized by second branchial arch anomalies (branchial cysts and fistulae),

malformations of the outer, middle and inner ear associated with sensorineural, mixed or conductive hearing loss, and the absence of renal abnormalities. Typical ear findings consist of malformed auricles (e.g. lop or cupped ears), preauricular pits and/or tags, and middle and/or inner ear dysplasias (inculding cochlear, vestibular and semicircular channel hypoplasia, malformation of the ossicles and of middle ear space). 